\title{
DESVENTURAS DA EDUCAÇÃO BRASILEIRA E AS 'REFORMAS' ATUAIS: EDUCAR PARA A PRODUTIVIDADE DO TRABALHO
}

\author{
Misfortune OF BRAZILIAN EDUCATION AND CURRENT \\ 'REFORMS': EDUCATION FOR LABOR PRODUCTIVITY
}

\begin{abstract}
Maria Carolina Pires de Andrade Mestranda em Educação pela Universidade Federal do Rio de janeiro. Rio de Janeiro - RJ - Brasil. carolina.andradep@gmail.com

Bruno Gawryszewski Doutor em Educaçấo pela Universidade Federal do Rio de Janeiro. Docente na mesma universidade. Rio de Janeiro - RJ - Brasil.

brunogawry@gmail.com
\end{abstract}

\begin{abstract}
Resumo: O artigo aborda as 'reformas' Base Nacional Comum Curricular (BNCC) e o Novo Ensino Médio (NEM). O trabalho visa compreender a simultaneidade das reformas educacionais com tantas outras em curso. À luz do método materialista histórico e dialético de investigação, analisamos (I) o conteúdo das 'reformas'; (II) o discurso propalado às massas com vistas à legitimaçâo de ambas (BNCC e NEM); (III) a conjuntura econômica, política e social de sua alavancagem; (IV) as recentes propostas de organismos internacionais como OCDE e Banco Mundial, para solucionar a crise. Tratase de uma análise teórica que busca dialogar o texto legal das 'reformas' e dos relatórios de organismos internacionais com a Teoria do Valor-Trabalho de Marx, mediado por referenciais que tratam das particularidades do capitalismo dependente, como Florestan Fernandes. Concluímos que (I) o conteúdo das propostas educacionais contradiz o discurso que as legitima, e apresenta ainda ressonância nas diretivas dos organismos internacionais; (II) essas reformas atendem às necessidades candentes das fraçóes da burguesia brasileira, que vem operando reformas na estrutura e na superestrutura do bloco histórico com vistas à manutenção de sua supremacia.
\end{abstract}

Palavras-chave: Crise. Políticas Públicas em Educação. Produtividade do Trabalho. Reformas Educacionais.

AbSTRACT: The article deals the educational 'reforms', especially the National Common Core and New High School. The aim of this study is to understand the simultaneity of educational "reforms", in the face of the consolidation of a turbulent and truculent economic, political and social situation. In the light of the historical and dialectical materialistic method of inquiry, we analyze (I) the content of the 'reforms'; (II) the speech spread to the public with the aim of legitimizing both; (III) the economic, political and social scenario that boosted such reforms; (IV) the recent proposals of 
international organizations, such as the OECD and the World Bank, to solve the crisis. It is a theoretical analysis that seeks to dialogue the law of 'reforms' and reports' international organizations with Marx's Value-Work Theory, mediated by references that deal with the particularities of dependent capitalism, such as Florestan Fernandes. We conclude that (I) the content of the educational proposals contradicts the discourse that legitimizes them, and such proposals are in line with the directives of the international organizations; (II) these reforms meet the burning needs of the fractions of the Brazilian bourgeoisie, which has been operating reforms in the structure and superstructure of the historical bloc with a view to maintenance of its supremacy

\section{Introdução}

Este texto versa sobre duas das principais 'reformas' educacionais em curso, quais sejam, a Base Nacional Comum Curricular (BNCC) e o Novo Ensino Médio (NEM). O destaque conferido a essas 'reformas' específicas se baseia na nossa compreensão de que ambas indicam as similitudes existentes entre a proposta pedagógica hegemônica e as necessidades candentes do capital e de suas personificaçóes.

Postas em marcha ainda no governo do Partido dos Trabalhadores, essas 'reformas' educacionais ganharam novo impulso após a deflagraçáo da recessão econômica em 2015 e o golpe jurídico-parlamentar-midiático de 2016. Sob a égide da urgência em resolver a assim chamada crise da educação, o NEM foi instituído via medida provisória em 2016; já a BNCC, mesmo incompleta, tramitou no Conselho Nacional de Educaçáo (CNE) e foi aprovada em 2017, contendo diretrizes apenas para a educaçáo infantil e o ensino fundamental. A BNCC do ensino médio segue em elaboração e ambas têm sido veemente repudiadas por sindicatos e entidades de defesa da educação.

A 'crise da educação' brasileira não é um diagnóstico novo, mas sim constância de uma sociedade que perpetua condiçóes estruturais residuais para grande parcela da classe trabalhadora. Assim, assumem historicamente diferentes roupagens e são alvo de sucessivas 'reformas' (geralmente inconclusas e sobrepostas), direcionadas a atender demandas que variam da pressão da classe trabalhadora por escolarização às necessidades do capital de ajustar a formaçáo da força de trabalho às exigências de sua reprodução ampliada. Nos últimos trinta anos, ainda que se tenha ampliado o acesso da classe trabalhadora à escola, as po- 
líticas de universalização vêm se materializando como massificação do tipo "periférico dependente" (MAGALHÃES; MOTTA, 2015), cujas características mais notáveis são o estreitamento curricular, o cerceamento do trabalho docente e a consolidaçáo do sistema avaliativo padronizado e em larga escala.

Tendo em vista um senso comum em que são atribuídas como causas a às mazelas econômico-sociais a baixa qualidade e a desigualdade de oportunidades na educação, a justificativa burguesa-estatal para as 'reformas' em curso não foge a esses termos: a implementação da BNCC garantirá a qualidade educacional e a igualdade de oportunidades, assim como o NEM é necessário para modernizá-lo e torná-lo atraente para os jovens.

Compreendemos, entretanto, que outras questóes subjazem às'reformas'. Do nosso ponto de vista, malgrado os problemas reais que perpassam a educação (como a evasão e a repetência), o movimento da classe dominante é uma operação ideológica, já que concebe problemas estruturais como anomalias efêmeras e que propõe soluções a partir de uma concepção de educação e de mundo particular aos grupos internos da própria classe dominante (GRAMSCI, 2000). Nessa direção, tentaremos demonstrar que (I) as 'reformas' educacionais representam ajuste na conformação psíquica, física, ideológica e social da classe trabalhadora, imperativas diante dos efeitos sociais da crise do capital, e (II) seu conteúdo guarda similitudes com as diretivas educacionais de organismos internacionais (OI) como Banco Mundial (BM) e Organização para a Cooperação e Desenvolvimento Econômico (OCDE), as quais por sua vez, em diversos aspectos, atendem às necessidades candentes da burguesia brasileira.

\section{Uma educaçáo para a produtividade da força de trabalho}

De acordo com a Confederação Nacional da Indústria (CNI), apesar das açóes destinadas à educação nos últimos trinta anos, os "dados do Índice de Desenvolvimento da Educação Básica (IDEB) mostram que a educação brasileira avança a passos mais lentos que o esperado." (CONFEDERAÇÃO NACIONAL DA INDÚSTRIA, 2018, s./p.). 
As dificuldades de aprendizagem são justificadas, pelas frações burguesas, pelo currículo ultrapassado, conteudista e desmotivador, o qual faz com que jovens percam o interesse pela escola tão logo percebam que nada do que ali aprendem lhes é útil, nem mesmo para conseguir uma ocupação. Assim, os jovens deixam o ensino médio sem se sentirem preparados para atuar no mercado (FONTOURA, 2017), que, apesar deoferecer oportunidades, não encontra mão-de-obra qualificada (JORNAL HOJE, 2015). As 'reformas', então, seriam essenciais à resoluçáo do problema, pois ao flexibilizar o currículo dotariam o jovem de suposta liberdade e protagonismo na sua trajetória formativa (BRASIL, 2018).

As razões acima são massivamente propaladas às massas. Entretanto, há uma razão que, embora não difundida nos meios de comunicação, tem sido propugnada em relatórios de OI e entidades do setor produtivo como problema educacional: a baixa produtividade da força de trabalho brasileira. Esta, do ponto de vista burguês, seria decorrente da formação inadequada da força de trabalho, incapaz de atender às demandas do mercado. Nessa perspectiva, Cláudio Moura e Castro, representante do empresariado2, afirmou à CNI que um

novo patamar de competitividade do Brasil depende de maior qualidade da educação [porque esta] impacta diretamente na inserção dos brasileiros no mercado de trabalho, na produtividade da indústria e em sua capacidade de inovação. Esses avanços podem ser alcançados a partir de iniciativas como [...] a implantação da BNCC. (CONFEDERAÇÃO NACIONAL DA INDÚSTRIA, 2018, s./p.)

Expusemos apenas uma parte da amálgama de justificativas em prol das 'reformas'. Ainda assim, é inegável que a sua legitimidade se ancora na necessidade de ajustar a educaçáo escolar para garantir o aumento da produtividade do trabalho e melhores condiçóes de competição no mercado internacional, para além de resolver os problemas mais imediatos da educação. Vejamos, então, o conteúdo das 'reformas'. 


\section{Base Nacional Comum Curricular e Novo Ensino Médio: origens e propostas}

A BNCC é documento de caráter normativo que define o conjunto de competências e habilidades que todos os alunos devem desenvolver e têm o direito de aprender em cada série da educação básica. Para seus construtores, a Base não se confunde com o currículo; é antes um elemento norteador para revisão de todos os currículos das escolas do Brasil (CASTRO, 2017). Desse modo, os currículos serão formados por uma parte majoritária e nacionalmente homogênea, e por uma parte diversificada, a ser definida por cada sistema de ensino.

Apesar dos debates em torno de uma base comum nos anos 1980, esta passou a ser discutida a partir da divulgaçáo da sua primeira versáo em setembro de 2015. Antes disso, porém, em 2013 foi fundada a organização empresarial que tomou a dianteira dos processos relativos à construção e implementação da BNCC, qual seja, o Movimento pela Base Nacional Comum (MPB), cuja rede de apoio institucional é composta instituiçóes como CENPEC, Fundação Roberto Marinho, Instituto Ayrton Senna, Itaú BBA, Todos Pela Educação e Instituto Natura. Após a divulgação dessa versão, foi aberto um período de consulta pública, seguido da divulgação da segunda versão, em abril de 2016. Precisamente um ano adiante, já no governo Temer, foi divulgada uma terceira versão (BRASIL, 2017a), parcial (sem o ensino médio), que tramitou no CNE mesmo incompleta. Em dezembro de 2017, uma versão semelhante, mas não idêntica, fora aprovada pelo Conselho ${ }^{3}$. Desde então as escolas têm até dois anos para reformularem seus currículos de forma a atender as exigências da BNCC. $\mathrm{Na}$ reuniáo do dia 4 de dezembro de 2018, o CNE aprovou a BNCC para o ensino médio e seguiu para homologação do Ministro da Educação Rossieli Soares.

O documento estabelece um conjunto de competências gerais que, em suma, representam os fins a serem perseguidos pela abordagem dos componentes curriculares em todas as etapas. Dentre tais competências estão "Conhecer-se, apreciar-se e cuidar de sua saúde física e emocional [...] reconhecendo suas emoçóes e as dos outros, com autocrítica e capacidade para lidar com elas", além de "exercitar a empatia, o diálogo, a resoluçáo de conflitos e a cooperação" e "agir pessoal e coletivamente com 
autonomia, responsabilidade, flexibilidade, resiliência e determinação.” (BRASIL, 2017b, p. 10)

Outro fundamento definido é o 'Compromisso com a Educação Integral',o que significa, na BNCC, propor uma educação que estimule o jovem a aplicar seus conhecimentos na vida real, permitindo-o ser protagonista "na construção de seu projeto de vida", já que, no "novo cenário mundial, reconhecer-se em seu contexto histórico e cultural, comunicarse, ser criativo, analítico-crítico, participativo, aberto ao novo, colaborativo, resiliente, produtivo e responsável requer muito mais do que o acúmulo de informaçôes." (op.cit., p. 15).

A versão aprovada define cinco áreas de conhecimento para o ensino fundamental, para as quais foram definidas competências gerais da área e específicas do componente curricular, bem como as habilidades para cada ano desta etapa. Ainda que seja a segunda parte do mesmo documento, a versão da BNCC do ensino médio não segue esse padrão, pois se entende que nessa etapa o currículo deve ser flexível a fim de garantir autonomia de escolha de percurso formativo aos estudantes (BRASIL, 2017b). Dessa forma, a proposta de BNCC para o ensino médio vincula as competências gerais da educaçáo básica a quatro áreas, cada qual definida as suas respectivas habilidades.

O arcabouço teórico-pedagógico da BNCC está firmemente presente na Lei no $13.415 / 2017$, que instituiu a 'reforma' do ensino médio. Do ponto de vista organizacional, a lei se assenta em uma anunciada ampliação da carga horária, propondo o aumento das atuais 800 horas para 1.400 anuais, atingindo pelo menos 1000 horas anuais em, no máximo, cinco anos. A lei define a BNCC como norteadora a partir da flexibilização curricular das trajetórias formativas e garante que ela ocupará, no máximo, 1.800 horas dessa etapa escolar. Além disso, a lei discrimina como componente obrigatório nos três anos apenas o ensino de português e matemática (BRASIL, 2017c).

O sentido formativo indicado pela Lei $n^{\circ}$ 13.415/2017 se ampara no estímulo ao projeto de vida e competências cognitivas e socioemocionais, já que "os currículos do ensino médio deverão considerar a formação integral do aluno, de maneira a adotar um trabalho voltado para a construçáo de seu projeto de vida e para sua formação nos aspectos físicos, cognitivos e socioemocionais." (id.ib.). Nesse sentido, tanto a BNCC quanto o 
NEM nos parecem apontar para a capacitação ${ }^{4}$ de um trabalhador que suporta incertezas e mudanças abruptas recorrentes, sobretudo em um contexto de aplicação de 'reformas' que implicam diminuição de direitos (GAWRYSZEWSKI, 2017).

$\mathrm{O}$ destaque conferido à noção de competência remete aos anos 1990, quando esta repercutiu no debate curricular e na prática pedagógica, sobretudo pelo entendimento de que a escola, mais do que transferir conhecimentos, deveria construí-los junto com o estudante. O Relatório Jacques Delors (UNESCO, 1996) foi o principal norteador dos princípios formativos para o século XXI, assentando-se no desenvolvimento de competências cognitivas: interpretar, refletir, pensar abstratamente, generalizar aprendizados. A educação fora alçada à condição de proporcionar a (con) formação dos indivíduos suscetíveis às mudanças bruscas na sociabilidade humana, na utilização das tecnologias e na formação para o mundo do trabalho. Nesse cenário, o Relatório já demonstrava a relevância da educação para incremento da produtividade a partir da ideologia do capital humano (MOTTA, 2008), dada a preocupação candente com a instabilidade e precariedade marcante do século. Diante das sucessivas inovaçôes, a educação deveria favorecer a flexibilidade, pois o modelo curricular baseado em diplomas de qualificaçóes rígidas estaria fadado à obsolescência. Em resumo, as competências eram concebidas como "uma espécie de coquetel individual, combinando a qualificação, em sentido estrito, adquirida pela formação técnica e profissional, o comportamento social, a aptidão para o trabalho em equipe, o gosto pelo risco [...]" (op.cit., p. 94)

Compreendemos que o exposto acima sintetiza as características centrais do projeto de capacitação da força de trabalho em curso que, respaldado pelos OI, forja as condiçóes estruturais e superestruturais de sustentação das relaçóes sociais capitalistas diante das novas formas de trabalho precarizadas, instáveis e flexíveis (CASTELO, 2011). Caberia, então, à educação "fazer com que cada indivíduo saiba conduzir o seu destino, num mundo onde a rapidez das mudanças se conjuga com o fenômeno da globalização." (UNESCO, 1996, p.105).

Ao que parece, o que ganha força nos últimos anos atende por competências socioemocionais, e significa um plus especial às competências cognitivas. Elas envolvem a capacidade do sujeito de se relacionar com outras pessoas, com autoconhecimento, estabilidade emocional, re- 
siliência, sociabilidade e abertura ao novo (ORGANIZAÇÃO PARA A COOPERAÇÃO E DESENVOLVIMENTO ECONÔMICO, 2015), o que parece assumir função essencial na conjuntura atual.

\section{A conjuntura de construção das 'reformas' educacionais}

O segundo mandato do governo Lula (2007-2010)iniciou sob a égide do neodesenvolvimentismo,um período de crescimento econômico. A esplêndida aceleração da economia chinesa favoreceu o mercado internacional, possibilitou superávits sucessivos na balança comercial brasileira e alguns alívios imediatos à classe trabalhadora no que tange à 'questão social's. Embora não tenham sido abandonadas as bases neoliberais, o Estado interveio para garantir a competitividade das empresas nacionais, sobretudo no auge da crise deflagrada nos Estados Unidos em 2008-2009. Os impactos da terceira grande depressão ${ }^{6}$ do capitalismo mundial puseram freio ao ciclo de crescimento econômico brasileiro durante o primeiro mandato presidencial de Dilma Rousseff (2011-2014). Potencializados pela estratégia macroeconômica recessiva adotada no seu segundo mandato (2015-2016), impuseram-se como barreira à continuidade do projeto neodesenvolvimentista, demonstrando a impossibilidade de evitar crises econômicas meramente pela manipulação de ferramentas da política macroeconômica.

No primeiro mandato da presidenta, a redução das taxas de rentabilidade dos setores economicamente hegemônicos (exceto o bancário e o de alimentos e bebidas) ocorreu pari passu à redução das taxas de desemprego e ao crescimento do salário mínimo real (PINTO et al, 2015). Isso mudou em 2014, quando a desaceleração do crescimento econômico se transformou em estagnação. Malgrado a intensificação das greves trabalhistas e as jornadas de junho de 2013, a presidenta foi reeleita. Então, as fraçóes burguesas, percebendo o Estado falhar na garantia das condiçóes prévias de acumulação de capital, intensificaram a pauta em prol da redução do custo da força de trabalho.

Para recuperar a confiança das fraçóes burguesas, Dilma escolheu o economista Joaquim Levy ${ }^{7}$ como Ministro da Fazenda e aplicou enérgicas medidas de ajuste fiscal, com a restrição de benefícios previ- 
denciários e trabalhistas. Tal medida fora tomada em um cenário de redução dos investimentos da Petrobrás, alta inflacionária, exacerbação da queda na arrecadação de impostos e trajetória ascendente do desemprego. Todavia, o ortodoxo ajuste acarretou a perda do pouco apoio da classe trabalhadora ao seu governo, doravante insatisfeita com a contração do consumo e a diminuição da renda familiar. Já a burguesia brasileira náo hesitava em demonstrar que a urgência do ajuste fiscal e das 'reformas' não era mais possível sob a égide petista (MARQUES, 2016). Assim, o descompasso das fraçóes internas do bloco no poder com as contradiçôes internas ao sistema partidário e o adensamento político tomado pela OperaçáoLava-Jato, que teve crescente apoio dos mais diversos estratos da sociedade, criaram as condiçóes favoráveis para o golpe de 2016 e para a retomada de uma guerra de posiçáo aberta pela classe dominante.

A proposição das'reformas' pelo governo de Michel Temera partir do segundo semestre de 2016 se deu sob o pretexto de superar a crise e "assegurar a saúde das contas públicas e a estabilidade política, de modo a atrair os investimentos internacionais." (SAFATLE, 2017, s./p.) A despeito da aprovação de algumas delas, como o teto limite para o gasto público com as despesas primárias (Emenda Constitucional 95/2016) e a fragilização das leis trabalhistas (Lei 13.467/2017), a melhora dos indicadores é tímida e inexpressiva. Não obstante a crise política que mantém o mandato presidencial de Michel Temer em constante corda bamba, as fraçóes burguesas não hesitam em desfraldar as bandeiras de que a agenda de 'reformas' deve ser preservada por se tratar de iniciativa baseada no bem comum da nação ${ }^{8}$.

O discurso pastiche de 'fim da crise' não encontra materialidade na conjuntura atual, que para a classe trabalhadora segue truculenta, com vultosos índices de desemprego, estagnação da renda e exacerbação da criminalidade. Por isso, entendemos que as 'reformas' educacionais não são eventos que destoam em relação a outros da atual conjuntura. Dialeticamente, a situação de crise no país náo deixa de lançar luz sobre o caráter contraditório da acumulação capitalista, tão mais violenta conforme o capital se expande. Vejamos, por ora, como as fraçóes burguesas, representadas pelos OI, entendem essa crise e suas soluçóes. 


\section{Diagnóstico e soluçóes sob a ótica dos organismos internacionais $(\mathrm{OI})$}

Dado esse cenário pouco animador, os OI não se abstiveram de diagnosticar e propor soluçôes à turbulência posta. Incrementar a produtividade é indispensável para o crescimento econômico. Da forma como é tratada recorrentemente pelos agentes da economia contemporânea, a produtividade é um indicador de eficiência das empresas, das indústrias e do próprio país na utilização de seus ativos existentes. Divide-se em duas medidas: a produtividade do trabalho e a produtividade total dos fatores. A metodologia mais difundida para mensurar a Produtividade do Trabalho (PT) divide o PIB pelo volume de horas trabalhadas por ano, de forma a medir a quantidade de riqueza gerada por cada trabalhador; por sua vez, a Produtividade Total dos Fatores (PTF) mensura o impacto combinado dos insumos do processo produtivo, considerando o emprego de capital humano (força de trabalho devidamente capacitada) e de capital físico (instalaçôes e matériasprimas). Nesses termos, "a evolução da PTF pode ser encarada como uma medida econômica do progresso técnico.” (BANCO MUNDIAL, 2018, p.8)

Em estudo específico sobre o Brasil, é defendido que o parco crescimento econômico nos últimos vinte anos só foi possível devido ao aumento quantitativo da força de trabalho e pelo progressivo acréscimo da escolaridade da população. Tais fatores teriam atenuado os efeitos deletérios da baixa produtividade do trabalho, pois a PTF caiu 1\% entre 1996 e 2015 e a produtividade do trabalho contribuiu apenas $0,6 \%$ ao ano (BANCO MUNDIAL, 2018 $)^{9}$, justamente pela não adequação da educação às demandas empresariais.

Faz-se necessário destacar que as fontes consultadas estabelecem uma relação distorcida entre educação - tratada como capital humano - e mercado de trabalho. Nessa perspectiva, a capacitação profissional é inadequada às empresas, porque torna "os retornos irrisórios. Isto ocorre, em parte, porque o trabalho é mal alocado e - ainda mais importante - porque o capital é mal alocado; isso impede que o capital humano seja utilizado da melhor forma possível." (BANCO MUNDIAL, 2018, p.64). Assim, advoga-se uma 'reforma' educacional que proporcione aumento da pro- 
dutividade do trabalho por conta de um capital humano mais capacitado. Para a OCDE, o plus no capital humano perpassa o desenvolvimento das competências socioemocionais que, além de terem um efeito positivo sobre as competências cognitivas, promovem também a equidade educacional, já que as crianças mais pobres precisam de suporte "para alcançar as mesmas oportunidades na vida que seus pares mais favorecidos.” (ORGANIZAÇÃO PARA A COOPERAÇÃO E DESENVOLVIMENTO ECONÔMICO, 2015, p. 21)

A OCDE vem promovendo estudos e parcerias com instituiçóes de diversos países, de modo que a agenda das competências socioemocionais possa ser ampliada e disputada como política pública educacional local. No Brasil, seu principal aliado é o Instituto Ayrton Senna, que há vinte anos logra êxito na venda de materiais didáticos, tecnologias educacionais e assessoramento para órgãos estatais na área de educação. Defende a $\operatorname{OCDE}(2015$, p. 18) que:

As crianças precisam de um conjunto equilibrado de competências cognitivas e socioemocionais para se adaptar ao mundo atual, cada vez mais exigente, imprevisível e mutante. Aquelas capazes de responder com flexibilidade aos desafios do século 21 têm mais chance de serem prósperas, saudáveis e felizes. As competências socioemocionais são úteis para enfrentar o inesperado, atender múltiplas demandas, controlar os impulsos e trabalhar em grupo.

Indubitavelmente, os jovens constituem o público-alvo prioritário das açóes educacionais, mormente considerando a crise capitalista brasileira. Tendo em vista a dificuldade de recuperação dos níveis de emprego e renda, o desenvolvimento de competências é tido como vacina para que as frustraçôes dos jovens não constituam empecilhos a si mesmos, pois

[...] pessoas com um nível mais alto de competências tem maiores chances de receber mais investimentos em educação. Os pais podem investir mais nas competências dos seus filhos se eles mostrarem um progresso promissor em seu desenvolvimento. (op.cit., p.77) 
O investimento nos segmentos mais vulneráveis (jovens, inclusive) foi promovido pelo Programa das Naçóes Unidas para o Desenvolvimento (PNUD), em seu relatório anual de 2014. Neste, foram apontados horizontes em resposta aos efeitos acarretados pela profunda crise econômica que atingiu seu estopim nos países centrais do capitalismo em 2008/2009 e que lançou parcelas expressivas da sociedade à própria sorte, com reduzida capacidade de reação diante de adversidades tão incisivas (PNUD/ONU, 2014). Conforme o PNUD, a emergência de novas ameaças implicaria a necessidade de respostas baseadas em açóes coletivas que congreguem Estados nacionais, organizações internacionais, sociedade civil e empresas privadas em prol de construir um sistema global mais resiliente. (op. Cit., 2014) A resiliência humana está designada pelo PNUD/ONU (2014, p.14) como uma forma de "assegurar que as pessoas façam escolhas sólidas, agora e no futuro, que as habilitem a enfrentar e a adaptar-se a adversidades." Logo, é posto na ordem do dia um "desenvolvimento humano resiliente", pois possibilita aos "indivíduos a viverem de acordo com o seu potencial e faz aumentar a produtividade porque aumenta a capacidade dos indivíduos para lidarem com os choques. Os indivíduos mais instruídos têm mais facilidade, por exemplo, em mudar de emprego." (op.cit., p.97). Nesse sentido, a inserção dos jovens neste "mundo complexo" do trabalho torna-se elemento crucial para os $\mathrm{OI}$ em prol da manutenção da governabilidade e da coesão social.

No entanto, aumentar a produtividade da força de trabalho não requer apenas competências socioemocionais. É preciso que os estudantes disponham das competências cognitivas requeridas por seus empregadores. O Banco Mundial cita as iniciativas mais recentes do governo Temer como apontamentos que produziram resultados satisfatórios (como a introdução de um currículo baseado em competências e a ampliação da escola em tempo integral) e prescreve que:

[...] uma estratégia bastante eficaz para desenvolver ainda mais as competências é aumentar o protagonismo das empresas, para que elas ajudem a garantir que os trabalhadores tenham as habilidades que as empresas exigem. Isso foi confirmado pelos resultados positivos do Sistema S, administrado pela indústria, e do subprograma PRONATEC-MDIC - que 
consideraram explicitamente as informaçôes fornecidas pelas empresas ao decidirem sobre o conteúdo e as competências oferecidas nos cursos - muito embora o custo-efetividade desses programas ainda precise ser melhor avaliado. Outros prestadores de treinamento, bem como outros ramos da iniciativa PRONATEC que não contam com serviços informados pela demanda, apresentaram resultados decepcionantes ${ }^{10}$. (BANCO MUNDIAL, 2018, p. 65 - grifo nosso)

A nosso ver, os caminhos atualmente apontados para aumentar a produtividade agudizam a relação entre mercado e educação. Embora seja um documento recente, trata-se certamente de uma diferença sutil, mas significativa: o relatório não sugere que a educação desenvolva competências a serem convertidas em qualidades gerais para um mercado de trabalho abstrato, como concebe a clássica concepção econômica de educação. O que o Banco Mundial aponta é a necessidade de a educação se vincular às empresas, pois ao desenvolver as habilidades requeridas por elasse geraria, consequentemente, um aumento de sua capacidade produtiva. Afinal, o sucesso atribuído ao subprograma PRONATEC-MDIC deriva do fato de que ele considerava "as informaçóes fornecidas pelas empresas ao decidirem sobre o conteúdo e as competências oferecidas nos cursos.”. São hipóteses dedutivas pensar que: (I) o conteúdo formação da classe trabalhadora, tendencialmente, será pré-definido pelas grandes empresas, e (II) as 'reformas' educacionais, sobretudo curriculares, seguirão nessa direção. Além disso, decerto que o Banco não está sugerindo que as empresas aumentem seus gastos com essa capacitação, mas que, tal como o PRONATEC, seja financiada pelo fundo público ${ }^{11}$.Cabe ratificar que uma capacitação em sintonia com as necessidades empresariais não se restringe apenas à força de trabalho ocupada, mas também ao Exército Industrial de Reserva ${ }^{12}$.

Noutros termos, essas diretrizes aprofundam a 'mercantilizaçáo da educação' na medida em que concebem a educação, ideologicamente, como puro meio de capacitar a força de trabalho, sob a ilusão de que essa capacitação é necessária à valorização da capacidade de trabalho humana. $\mathrm{Na}$ realidade, a capacitação encomendada pela empresa exacerba a alienação do valor de uso da mercadoria força de trabalho pelo seu detentor, 
ao passo que potencializa o valor de uso dessa capacitação àquele que a efetiva. Portanto, na ótica do Banco Mundial, trata-se não de comprar uma força de trabalho qualquer no mercado, mas de encomendara força de trabalho com competências produzidas sob medida para atender às suas necessidades reais.

As 'reformas' também abrem espaço para a 'mercadorização da educação', uma vez que as grandes empresas podem comprar pacotes formativos variados do Sistema $S$ para capacitação de seus empregados. Capacitação que pode e deve, sob tal ótica burguesa, ser conferida, minimamente, também a uma parte da populaçáo reserva que deve tanto ser passível de ser contratada em períodos de expansão do mercado quanto de exercer pressão negativa sobre o valor da força de trabalho.

É inegável que há intenção de manter a coesão social indispensável à acumulação em geral, e, portanto, de conformar aqueles que, a despeito de sua capacidade produtiva, constituem a parcela dos desempregados e desalentados. É válido lembrar ainda que o peremptório aumento da produtividade do trabalho no âmbito das grandes empresas e o seu consequente e progressivo acúmulo de riquezas tende a apresentar consequências severas para a classe trabalhadora, já que, como sinalizou Marx (2017, p. 877), "a acumulação de miséria [é] correspondente à acumulação de capital. Portanto, a acumulação de riqueza num polo é, ao mesmo tempo, a acumulação de miséria, o suplício do trabalho [...] no polo oposto.”

\section{À guisa de conclusão}

Compreendemos que o NEM e a BNCC não são eventos fortuitos em meio à avalanche de 'reformas' postas no tempo presente. Não ao acaso, elas são trazidas à tona em uma conjuntura de crise, na qual se acirram as disputas pelo controle do acesso ao fundo público, com fins de recuperação das taxas de lucro. Por certo, tais mecanismos atingem diretamente a classe trabalhadora, condenando grande parte desta classe à miserabilidade, à degradação moral e à ignorância.

As preocupaçóes com o acesso ao conhecimento historicamente acumulado e as ferramentas de compreensão do mundo não subjazem às propostas formativas das 'reformas', já que os currículos escolares são, por 
meio delas, estreitados. No entanto, há um movimento ininterrupto de amortização dos altos índices de desemprego, pobreza e violência, sobretudo entre os jovens. Conforme sinalizado nas diretivas dos OI, a barbárie social e a possibilidade de tensionamento da coesão social continuam a preocupar as fraçôes burguesas, de forma que toda e qualquer medida 'contracorrente' faz-se imperativa, independentemente do seu caráter antidemocrático, truculento e repressivo.

Compreendemos que as 'reformas' educacionais são sustentadas por um tripé de necessidades, todas vinculadas ao desejo de destravar a acumulação de capital. É certo que as frações do capital ensejam o aumento da produtividade do trabalho que, proporcionando a redução da relação gasto/produto, permite melhorar as condiçóes de competitividade no mercado. A massiva, restrita e aligeirada capacitaçáo da força de trabalho em prol do aumento da produtividade do trabalho, na perspectiva dos OI, permite que os trabalhadores produzam mais valores em menos tempo. Isto tem como desdobramentos: (I) a ociosidade forçada de uma parcela da classe trabalhadora, de forma que um menor contingente de empregados produza a mesma quantidade de riquezas, enquanto a população reserva pressiona constantemente o valor da força de trabalho para baixo e/ou (II) o aumento substancial da quantidade de riquezas produzidas com maior eficiência, permitindo, no caso da produção de serviços e mercadorias, a redução dos seus valores e melhores resultados na concorrência, e(III), como demonstrou Marx (2017), combinar o aumento da produtividade do trabalho às formas absolutas e relativas de extração de mais-valor a fim de incrementar tenazmente o grau de exploração da força de trabalho e o tempo de trabalho excedente, proporcionando acréscimos na riqueza produzida socialmente e apropriada privadamente.

Uma necessidade latente das fraçôes burguesas é movimentar cada vez maiores massas de capital, já que "quanto mais desenvolvido o capital [...] tanto mais extraordinariamente tem de desenvolver a força produtiva do trabalho para valorizar-se em proporção ínfima." (MARX, 2011, p. 426) Considerando-se que é característica das crises capitalistas o estorvo da reprodução ampliada e a dificuldade de gerar e movimentar capital, a busca pela transformação do fundo público em lucro privado, inclusive pela capitalização desse fundo, não é de surpreender. A nosso ver, as 'reformas' educacionais não deixam de contribuir para tal, uma vez que o 
Estado contrata empresas para gerir e alavancar as medidas e obriga, direta ou indiretamente, à produção de novos materiais didáticos e pacotes de formação docente. Ilustra a afirmação acima a contratação da Fundação Carlos Alberto Vanzolini pelo MEC, em 23 de março de 2017, ao custo de R\$ 18.923.297,00, para "Prestação de serviços especializados para a gestáo integrada dos processos necessários à consolidação, disponibilização, divulgação e discussão da $3^{a}$ versão da BNCC.” (BRASIL, 2017d).

Não menos importante é o fato de que tornar o trabalhador mais produtivo significa também capacitá-lo para lidar individual e passivamente com a barbárie social, de forma a preservar a coesão social. Inegavelmente, essa tarefa vem sendo cumprida pelo empresariado que, no exercício da sua capacidade técnica e dirigente, organiza o consenso, opera o conformismo das massas e se vale da coerção - estatal ou não - sempre que necessário (GRAMSCI, 2000). Não obstante, esse mesmo empresariado dirige e organiza seus aliados para a consolidação do projeto pedagógico hegemônico, qual seja, moldar a força de trabalho em fina sintonia com os interesses das mais variadas fraçóes burguesas ou, noutras palavras, das necessidades candentes da expansão capitalista. Tal necessidade vem sendo atendida, por exemplo, pela obrigatoriedade das competências socioemocionais no currículo da educação básica.

Para além desse tripé, a implementação do NEM atende a interesses há muito demandados pelo empresariado, como a vinculação dessa etapa de ensino a uma BNCC, a dita flexibilização dos itinerários formativos e a possibilidade de aproximação da oferta formativa com o mercado de trabalho. Nesse âmbito, o sentido de modernização e flexibilização se torna uma metáfora léxica para significar maior espaço para o empresariado incidir sobre os processos formativos da força de trabalho brasileira.

No escopo da BNCC, o projeto pedagógico se ampara em slogans questionáveis como igualdade de oportunidades, direito de aprender, liberdade de escolha ${ }^{13}$, cujo sucesso depende da capacidade de operar conhecimentos e de empreender, bem como de resistir e superar as adversidades. Tendo o Estado cumprido o papel de oferecer a oportunidade de acessar a educação, a corrida em direção ao sucesso profissional e à ascensão social dependerá do equilíbrio emocional subjetivo, da persistência e da capacidade de saber aproveitar as chances oferecidas. Esse discurso não é novo, por óbvio; o que nos parece relativamente novo são as sucessivas finalida- 
des postas em evidência pela burguesia internacional e brasileira, variando conforme as especificidades conjunturais.

Ratificamos que as 'reformas' educacionais fazem parte do projeto econômico e ético-político operado pela burguesia com vistas à manutenção da sua supremacia. No âmbito da luta política, destacamos que resistir às reformas não deve significar resistir às suas aparências ou consequências. Não estamos negando a importância de resistir aos seus impactos, já que ambas aprofundam as características perversas da educação brasileira. Sinalizamos apenas que as 'reformas' fazem parte de um conjunto mais abrangente de medidas que reafirmam o caráter antidemocrático e truculento de nossa burguesia. Outrossim, que as 'reformas' são apenas uma face da agudização das contradiçóes inerentes à sociedade capitalista. Por isso, afirmamos: barrar as "reformas" é barrar o desenvolvimento do capital.

\section{Notas}

1 Acrescentamos aspas em reformas por entendermos que elas não têm como propósito ampliar os direitos sociais, mas sim a esfera de atuaçáo do capital com menor regulação possível, por um movimento peremptório de retirada de direitos. Por isso, a denominação mais pertinente, do ponto de vista classista, seria a de contrarreformas. (Cf. COUTINHO, 2002)

2 Empresariado para nos referirmos a um seleto grupo de empresários, banqueiros, industriais, etc. que exercem a função de intelectuais orgânicos da classe dominante, assumindo posição de prestígio e confiança, exercendo a "capacidade técnica e dirigente" no âmbito das relaçôes sociais capitalista. Com essa expressão, fundamentada na concepção de intelectual em Gramsci (2000), buscamos abarcar a lógica empresarial - sua capacidade técnica que penetra em todas as esferas da relaçấo social por meio de vários mecanismos de controle - e, sobretudo, sua capacidade dirigente, de produção de vários tipos de consenso.

3 Embora o MEC e o MPB considerem as duas versóes de 2017 uma única versão, fazemos a opção por distingui-las como 2017a (abril) e 2017b (dezembro), tendo em vista que, embora sejam poucas, foram significativas as alteraçóes entre as duas versôes, à exemplo da inserçấo do Ensino Religioso na versão aprovada (2017b).

4 Compreendemos que a concepção hegemônica de processo formativo desde os anos 1990 reduz o processo à apreensão de competências e habilidades exclusivamente necessárias a um mercado de trabalho (formal ou informal) reduzido, flexível e de alta rotatividade. Por isso, denominamos como capacitação da força de trabalho.

5 Trata-se de uma categoria analítica consagrada na área do Serviço Social que designa um fenômeno social próprio do capitalismo como modo de produçáo dominante através de sua expressão na relaçấo antagônica entre as classes a partir do lugar que ocupam no processo produtivo, tendo como maior efeito deletério a apropriação privada pelos burgueses da riqueza socialmente produzida em detrimento da ampla maioria da sociedade. Cf. Pastorini (2004).

6 Depressão na economia capitalista global não é sinônimo de recessão. O Brasil passou por vários períodos de recessão econômica, nos quais houve a retração geral na economia. A história do capitalismo industrial é marcada por duas grandes depressôes; a primeira entre 1873 e 1898, que impulsionou o desenvolvimento do capitalismo monopolista e do imperialismo, e levou à 
Primeira Guerra Mundial; e a segunda entre 1929 e 1940, que levou ao surgimento do fascismo e a eclosão da Segunda Guerra Mundial (ALVES, 2018).

7 Joaquim Levy é doutor em Economia pela Universidade de Chicago, ocupou cargos no Fundo Monetário Internacional, no Banco Interamericano de Desenvolvimento e no setor bancário. Desde janeiro de 2016, após ter deixado o governo federal, assumiu posto de diretor do Banco Mundial.

8 Para exemplificar, podemos lembrar que, em julho de 2017, no auge da sucessão de denúncias contra Michel Temer - por conta da delação do controlador da empresa JBS, Joesley Batista - o ex-presidente do Banco Central, Armínio Fraga, afirmou sem hesitar que a saída de Temer não deveria atrasar o compromisso com a agenda econômica, pois "o mais importante é que as instituiçôes funcionem e resolvam a crise política e moral sem apelar para a economia." (SAFATLE, 2017, s/p)

9 Tal conclusão de declínio/estagnação é contestada por pesquisadores de economia como Barbosa Filho e Pessôa (2014). Ambos argumentam a formulaçáo hegemônica da queda da produtividade do trabalho a partir da década de 1980 padece de um problema metodológico, pois, a partir de 1992, a PNAD-IBGE passou a incorporar o trabalho não remunerado como ocupação, o que alargou a populaçáo tida como ocupada. Ao fazer o ajuste de excluir os trabalhadores não remunerados que trabalham menos de 15 horas por semana nas PNADs a partir de 1992, resultou que o crescimento da populaçấo ocupada fosse minimizado e houvesse uma queda menor no total de horas trabalhadas. Dessa forma, concluíram que a "produtividade do trabalho apresentou estagnaçáo na década de oitenta, teve leve aumento nos anos noventa e acelerou o ritmo de crescimento a partir de 2004" (BARBOSA FILHO; PESSÔA, 2014, p.164) e que padráo semelhante ocorreu na Produtividade Total dos Fatores, indicando que o maior crescimento do PIB brasileiro a partir de 2004 foi um evento no qual a evoluçấo da produtividade foi relevante.

10 O relatório do Banco Mundial cita a pesquisa de O'Connell et al. (2017), que concluiu que os programas de formação vocacional (como o Pronatec) muitas vezes são ineficazes porque não tinham qualquer vínculo com as necessidades futuras das empresas, resultado diferente obtido pelo Pronatec em parceria com o Ministério do Desenvolvimento, Indústria e Comércio (um programa orientado pela demanda de formação em competências bem alinhadas com as áreas das empresas) que teve resultado de um efeito causal sobre os empregos e rendimentos.

11 Segundo Motta e Frigotto (2017, p. 361), em 2014 a União transferiu para o Pronatec o "montante de $\mathrm{R} \$ 2.648 .668 .385,35$, sendo que $\mathrm{R} \$ 2.581 .208 .152,00$ foram destinados ao Sistema S. Até junho de 2015, em meio aos cortes na educação, tinham sido transferidos para o Pronatec, R \$ 551.413.899,65 e, desse montante, R \$ 518.393.229,20 foram destinados ao Sistema S."

$12 \mathrm{O}$ Exército Industrial de Reserva (EIR) refere-se a parte do proletariado que não é inserida no mercado de trabalho, pois é condenada à "ociosidade forçada em virtude do trabalho excessivo de outra parte" da classe trabalhadora. Ela é funcional ao Modo de Produção Capitalista na medida em que força sobremaneira a redução do valor da mercadoria força de trabalho, já que mantém a sua oferta em patamares superiores ao demandado pelo Capital. (MARX, 2017, p.716)

13 Este discurso é veementemente propalado por fraçôes capitalistas, desconsiderando que, na realidade, a lei prevê que a "oferta de diferentes arranjos curriculares" estará submetida à "possibilidade dos sistemas de ensino." (BRASIL, 2017c)

\title{
Referências
}

\begin{abstract}
ALVES, G. A longa depressão do século 21 e a era da barbárie social. Blog da Boitempo, publicado em 26 jan. 2017. Disponível em < https://blogdaboitempo.com. br/2017/01/26/a-longa-depressao-do-seculo-21-e-a-era-da-barbarie-social-i/>, acesso em 28 maio 2018.
\end{abstract}


BANCO MUNDIAL. Emprego e crescimento: a agenda da produtividade. Brasília: Grupo Banco Mundial, 2018.

BARBOSA FILHO, F. H.; PESSÔA, S.A. Pessoal ocupado e jornada de trabalho: uma releitura da evolução da produtividade no Brasil. Revista Brasileira de Economia, Rio de Janeiro, v. 68, n. 2, p. 149-169, abr./jun. 2014.

BRASIL.MEC, Ministério da Educação. Novo Ensino Médio: dúvidas. 2018.

Disponível em: <http://portal.mec.gov.br/component/content/article?id=40361 $>$. Acesso em: 28 set. 2018.

BRASIL. Ministério da Educação. Base Nacional Comum Curricular. Terceira versão. Brasília: MEC, 2017a. Disponível em <http://basenacionalcomum.mec.gov.br/images/ pdf/1_BNCC-Final_Introducao.pdf>. Acesso em: 20 set. 2018.

BRASIL. Ministério da Educação. Base Nacional Comum Curricular. Versão em tramitação. MEC, 2017b. Disponível em: <http://basenacionalcomum.mec.gov.br/ bncc-ensino-medio >. Acesso em: 01 out. 2018.

BRASIL. Lei no 13.415/2017, de 16 de fevereiro de 2017c. Altera as Leis no $\underline{\text { os }} 9.394$, de 20 de dezembro de 1996e institui a Política de Fomento à Implementação de Escolas de Ensino Médio em Tempo Integral. Diário Oficial da União: Brasília, 2017, 17 fev. 2017. Disponível em http://www.planalto.gov.br/ccivil_03/_ato2015-2018/2017/lei/L13415. htm>. Acesso em: 21 jul. 2017.

BRASIL. Diário Oficial da União. Publicação de em 23 de março de 2017d. Disponível em: <https://www.jusbrasil.com.br/diarios/DOU/2017/03/23 >. Acesso em 01 out. 2018.

CASTELO, R. O Social-Liberalismo: uma ideologia neoliberal para a "questão social" no século XXI. 380f. Tese (Doutorado em Serviço Social) - Escola de Serviço Social, Universidade Federal do Rio de Janeiro, 2011.

CASTRO, M. H. A Base não é currículo. O Globo, publicado em 12 de abril de 2017. Disponível em: < https://oglobo.globo.com/opiniao/a-base-nao-curriculo-21194267>. Acesso em 28 set. 2018.

CONFEDERAÇÃO NACIONAL DA INDÚSTRIA (CNI). Educação é agente transformador e fator de competitividade. Disponível em: <http://www.portaldaindustria. com.br/cni/canais/mapa-estrategico-da-industria/reportagem-especial/mapa-daindustria-2018-2022-educacao-e-agente-transformador-e-fator-de-competitividade/>. Acesso em 01 out. 2018.

COUTINHO, C. N. A época neoliberal: revolução passiva ou contra-reforma? Novos Rumos, Marília, Universidade Estadual Paulista, v.49, n.1, p.117-126, jan./jun. 2012. Disponível em <http://www2.marilia.unesp.br/revistas/index.php/novosrumos/article/ view/2383/1943>. Acesso em: 28 set. 2018. 
FONTOURA, J. O que os jovens gostariam de ter aprendido na escola sobre o mercado de trabalho. Revista Educação, publicado em $1^{\circ}$ de fevereiro de 2017. Disponível em: <http://www.revistaeducacao.com.br/o-que-os-jovens-gostariam-de-teraprendido-na-escola-sobre-o-mercado-de-trabalho>. Acesso em 28 set. 2018.

GAWRYSZEWSKI, B. Crises capitalistas e conjuntura de contrarreformas: qual o lugar do ensino médio? Revista Pedagógica, Chapecó, v 19, n. 42, p. 83-106, set./ dez. 2017.

GRAMSCI, A. Cadernos do Cárcere, volume 2. Rio de Janeiro: Civilização Brasileira, 2000.

JORNAL HOJE. Mercado oferece oportunidades, mas falta mão de obra qualificada. G1, publicado em 27 de abril de 2015. Disponível em: <http://g1.globo.com/ jornal-hoje/noticia/2015/04/mercado-oferece-oportunidades-mas-falta-mao-de-obraqualificada.html>. Acesso em 28 set 2018.

MAGALHÃES, L. K.; MOTTA, V. Tecnologia Social: massificação periféricodependente revestida pelo discurso de universalização da educação básica brasileira. In: ANDRADE, J.; PAIVA-GUTIERREZ, L.; OLIVEIRA, L. F. (Orgs.). O Estado brasileiro e a educação básica: os difíceis caminhos da universalização. Rio de Janeiro: Editora AMC Guedes, 2015. p. 173-194.

MARQUES, M. G. O fim do ciclo PT: do colaboracionismo de classe à ortodoxia neoliberal. SER Social, Brasília, Universidade de Brasília, v.18, n.38, p.48-67, jan./jun. 2016.

MARX, K. O capital: crítica da economia política, livro I. São Paulo: Boitempo, [1867] 2017.

MARX, K. Grundrisse. São Paulo: Boitempo, [1858] 2011.

MOTTA, V; FRIGOTTO, G. Por que a urgência da reforma do ensino médio? Medida Provisória no 746/2016 (Lei no 13.415/2017). Educação e Sociedade, Campinas, v. 38, no. 139, p.355-372, abr./jun. 2017.

MOTTA, V. Ideologias do capital humano e do capital social: da integração à inserção e ao conformismo. Trabalho, Educação e Saúde, Rio de Janeiro, vol.6, n.3,pp.549-572, 2008.

ORGANIZAÇÃO PARA A COOPERAÇÃO E DESENVOLVIMENTO ECONÔMICO (OCDE). Competências para o progresso social: o poder das competências socioemocionais. São Paulo: Fundação Santillana, 2015.

PASTORINI, A. A categoria “questão social” em debate. Sáo Paulo: Cortez, 2004. 
PINTO et. al, E. C. A guerra de todos contra todos: a crise brasileira. Texto para discussão, Instituto de Economia, UFRJ, fev. 2017. Disponível em http://www.ie.ufrj. br/images/pesquisa/publicacoes/discussao/2017/tdie0062017pinto-et-al.pdf. Acesso em: 09 set. 2018.

PROGRAMA DAS NAÇÓES UNIDAS PARA O DESENVOLVIMENTO. PNUD; ORGANIZAÇÃO DAS NAÇÓESS UNIDAS. ONU. Relatório do desenvolvimento humano 2014. Sustentar o progresso humano: reduzir as vulnerabilidades e reforçar a resiliência. Nova York: ONU, 2014.

SAFATLE, C. Para Armínio, saída de Temer náo deve atrasar retomada econômica. Valor Econômico, publicado em 12 jul. 2017. Disponível em <http://www.valor.com.br/ brasil/5034954/para-arminio-saida-de-temer-nao-deve-atrasar-retomada-economica $>$. Acesso em: 17 abr. 2018.

UNESCO. Organização das Nações Unidas para a educação, ciência e cultura. Educação: um tesouro a descobrir. Relatório para a UNESCO da Comissão Internacional sobre Educação para o século XXI. São Paulo: Cortez, 1996.

Recebido em 9 out. 2018 / Aprovado em I2 nov. 2018 Para referenciar este texto:

ANDRADE, M. C. P.; GAWRYSZEWSKI, B. Desventuras da educação brasileira e as 'reformas' atuais: educar para a produtividade do trabalho. EccoS-Revista Científica, São Paulo, n. 47, p. I05-I25. set/dez. 2018. Disponível em: <https://doi. org/10.5585/EccoS.n47.10716>. 
